\title{
Leci e Januário: escrevivências negras contemporâneas na música e fotografia ${ }^{1}$
}

\author{
Vilma Neres Bispo ${ }^{2}$ \\ Elisângela de Jesus Santos ${ }^{3}$
}

\begin{abstract}
Resumo: O trabalho em questão propõe articulações entre diferentes linguagens do campo artístico brasileiro no século XX. Para isso, realiza diálogo entre a produção cancional e fotográfica de Leci Brandão e Januário Garcia, pontuando elementos de escrevivências (EVARISTO, 2003; 2008). Por fim, aponta para as narrativas cancionais e fotográficas compostas para os discos Coisas do meu pessoal (Polydor/Polygram, 1977) e Essa tal criatura (Polydor, 1980) como produtos artísticos que abrigam poéticas narrativas reveladoras de subjetividades e lugares de memória vinculados às trajetórias e relações sociais de seus produtores, desnudando sentidos importantes para a construção de saberes, fazeres e artes com foco no prisma étnico-racial e de gênero.

Palavras-chave: Leci Brandão. Januário Garcia. Escrevivências negras.
\end{abstract}

Leci e Januário: black escrevivências in contemporary music and photography

Abstract: The work in question proposes articulations between different arts of the Brazilian field in the late twentieth century. In order to do so, he conducts a dialogue between the production of two contemporary black artists, Leci Brandão and Januário

\footnotetext{
${ }^{1}$ Recebido em 15/05/2017 e aprovado em 20/08/2017.

2 Mestre em Relações Étnico-Raciais pelo CEFET/RJ (2016). Jornalista e Fotógrafa. Atualmente é professora temporária na Universidade Federal do Espírito Santo (UFES).

${ }^{3}$ Professora e Pesquisadora no Programa de Pós-Graduação em Relações Étnico-Raciais (PPRER) e no Bacharelado em Línguas Estrangeiras Aplicadas às Relações Internacionais (LEANI) do Centro Federal de Educação Tecnológica "Celso Suckow da Fonseca" (CEFET/RJ), campus Maracanã. Pós-doutorada pelo Centro de Estudos Sociais (CES) da Universidade de Coimbra (2016). Doutora em Ciências Sociais (2013) e Mestre em Sociologia (2008) pela UNESP/Araraquara.
} 
|84|

Leci e Januário: escrevizências negras...

Garcia, to punctuate elements of escrevivências (EVARISTO, 2003; 2008). Finally, it points to the compositional and fotographic narratives for the discs Coisas do meu pessoal (Polydor/Polygram, 1977) and Essa tal criatura (Polydor, 1980) as artistic products that harbor poetic narratives revealing subjectivities and places of memory linked to the trajectories and social relations of its producers, important meanings for the construction of knowledges, practices and arts with a focus on ethnic-racial prism and gender.

Keywords: Leci Brandão. Januário Garcia. Black escrevivências.

Leci y Januario: escrevivencias negras contemporáneas en la música y la fotografía

Resumen: El trabajo en cuestión propone articulaciones entre diferentes lenguajes del campo artístico brasileño en el siglo XX. Para ello, realiza diálogo entre la producción cancional y fotográfica de Leci Brandão y Januário Garcia, puntuando elementos de escrevivências (EVARISTO, 2003; 2008). Por último, apunta a las narrativas cancionales y fotográficas compuestas para los discos Coisas do meu pessoal (Polydor/Polygram, 1977) y Essa tal criatura (Polydor, 1980) como productos artísticos que albergan poéticas narrativas reveladoras de subjetividades y lugares de memoria vinculados a las trayectorias y relaciones sociales de sus productores, desnudando sentidos importantes para la construcción de saberes, hacer y artes con foco en el prisma étnico-racial y de género.

Palabras-clave: Leci Brandão. Januário Garcia. Escrevivências negras.

Pela lente do amor

Sou capaz de entender

Os detalhes da alma de alguém

Pela lente do amor

Vejo a flor me dizer

Que ainda posso enxergar mais além...

(Gilberto Gil, "Lente do amor", LP O Luar, Warner, 1981)

Enquanto ato eternizado, uma imagem fotográfica carrega dimensão memorial. Este modo de expressão visual capta a vida humana a partir e de acordo com as formas, contextos e ângulos de visão dos grupos e pessoas produtoras. Processos semelhantes aos que ocorrem com a fotografia como (re)produção de uma visão de mundo específica, acontecem também em termos musicais, se pensarmos a linguagem musical como produtora de poéticas que resultam em textos estético-narrativos expressos na forma canto. 
O objetivo deste trabalho é realizar uma discussão transdisciplinar sobre o campo artístico brasileiro articulando fotografia e canção através das amarrações conceituais literárias de Conceição Evaristo. Refletimos sobre dimensões expressivas da subjetividade e da construção memorial coletiva de artistas contemporâneos, brasileiros negros, através dos trabalhos fotográficos de Januário Garcia e das letras de música de Leci Brandão. Trata-se de reflexão sobre processos de conotação e denotação da produção artística de negras e negros nos anos 1970 e 1980, para compor uma definição possível e potente de Movimento Negro no Brasil.

O texto realiza três movimentos: a) tem como pressuposto o conceito de escrevizência desenvolvido pela escritora Conceição Evaristo para evocar o sentido social da canção como palavra cantada; b) trata a fotografia como escrita, isto é, como (foto) escre(vivências) negras (cf. BISPO, 2016) para o caso do artivismo visual de Januário Garcia (1943-), e de vivências poéticas para tratar dos versos cancionais e formas discursivas (letras das canções) de Leci Brandão (1944-), observando como ambas as escrevizências expressam elementos e articulam discursos sobre as trajetórias estudadas; c) parte das imagens construídas para a veiculação comercial nas capas de discos e dos versos proferidos na forma cancional ${ }^{4}$ como instrumentos de artivismo e construção identitária.

\section{"me perguntaram: você tem status?"5}

Leci e Januário iniciam profissionalmente no campo artístico na década de 1970 na cidade do Rio de Janeiro. Coincidentemente, esse período da história brasileira é referência de luta do movimento negro contemporâneo, seja no campo da expressão simbólica e artística ou da ação política organizada. As trajetórias de Leci

\footnotetext{
${ }^{4}$ Aqui corresponde às letras das canções.

${ }^{5}$ Verso de "Status", faixa do LP Coisas do meu pessoal, 1977.
} 
$\mid 86$ |

Leci e Januário: escrevizências negras...

e Janu aproximam-se pela luta em combate ao racismo e pelo direito do sujeito negro de viver em liberdade, seja onde e como quiser estar e agir.

A 12 de setembro de 1944 estreia neste mundo Leci Brandão da Silva, mulher negra "brasileira bem-nascida em Madureira"6, filha de dona Lecy de Assumpção Brandão e Antonio Francisco da Silva. Criada em Vila Isabel, tem a própria trajetória marcada por bairros-lugares de memória e redutos de sambistas na cidade do Rio de Janeiro e em São Paulo. Leci Brandão, como é conhecida artisticamente, compôs a primeira canção, "Tema do amor por você", em $1965^{\prime \prime}$. Foi a primeira mulher a compor a ala de compositores da Estação Primeira de Mangueira ${ }^{8}$, após destacar-se, em 1970, no I Festival de Música da Gama Filho, universidade na qual trabalhava como secretária. Alcançou o segundo lugar com a música "Cadê Mariza", gravada em 1975 no seu primeiro compacto Antes que eu volte a ser nada, pelo selo Marcus Pereira. A canção retrata tema recorrente na obra de Leci: a trajetória de uma mulher periférica, empregada doméstica na zona sul carioca que deixa de ser passista da escola de samba para se tornar capa de revistas. Ao ocupar um espaço majoritariamente masculino na Mangueira, ela conta:

Eu já era compositora desde 1964, comecei a fazer música por causa de uma desilusão amorosa e o Zé Branco, componente da ala dos compositores da Mangueira, conhecido da minha família e que já sabia que eu era compositora, foi quem teve a ideia de me apresentar na ala. Nessa época, os compositores faziam

\footnotetext{
${ }^{6}$ Verso de "Seu João", faixa do LP Essa tal criatura, 1980.

7 Cf. Dicionário Albin da Música Popular Brasileira. Disponível em: $<$ http://www.dicionariompb.com.br/leci-brandao/dados-artisticos $>$. Acesso em: 28/05/2016.

${ }^{8}$ Grêmio Recreativo Escola de Samba Estação Primeira de Mangueira. Maiores informações institucionais em: <http://www.mangueira.com.br/a-mangueira/ historia/historia-da-mangueira/>. Acesso em: 28/05/2016.
} 


\begin{abstract}
reunião no centro da cidade, na garagem da Limpeza Urbana. Ele resolveu me apresentar lá e houve um espanto para os quase 40 homens de uma escola de samba tradicional e respeitada como é a Mangueira. Essa reunião, para você ter uma ideia, tinha o Pelado, o Turco, Mãe Léo, Tantinho, Jurandir, todo esse pessoal. Grandes baluartes da ala dos compositores da Mangueira estavam presentes 9 .
\end{abstract}

Inserida artisticamente no universo mangueirense, entre outros bairros repletos de bambas ${ }^{10}$, a relação de Leci com o universo do samba da Mangueira constitui legado familiar por matrilinearidade. Herdeira da avó, mãe e madrinha, todas mangueirenses, foi por conta delas que forjou o amor pela agremiação. Leci sempre teve sua mãe, dona Lecy, como referência primordial. A artista passou parte da infância vivendo com os pais numa casa de cômodos na rua Senador Pompeu no centro do Rio e ficava sob os cuidados de uma vizinha portuguesa, Esther, a dona Estelinha. Posteriormente, quando a família se muda para o bairro da Abolição, na zona Norte da cidade, Leci terá a avó materna, dona Ormevinda, como referência. Com a mudança para Vila Isabel, Lecizinha passa a estudar na mesma escola onde sua mãe trabalhava como servente (cf. SOUSA, 2016).

Januário Garcia Filho, ou simplesmente Januário Garcia, nasceu na cidade de Belo Horizonte (MG), em 1943, no auge da Segunda Guerra Mundial. Ele é filho de mãe mineira, dona Geralda da Mata Garcia, e de pai paulista, seu Januário

${ }^{9}$ Cf. Leci Brandão. Entrevista publicada na revista Raça. Disponível em: $<$ https:// revistaraca.com.br/leci-brandao-fala-da-vida-politica-em-entrevista/>. Acesso em: 18/10/2017.

${ }^{10}$ Conforme já notamos em outros trabalhos (cf. SANTOS, 2014a; 2014b), o termo "bamba" pode ser (auto)referencial para definir notórios e consagrados sambistas, geralmente do sexo masculino. Vários trechos cancionais da poética popular brasileira, sobretudo letras de samba, constituem metalinguagem dessa honrosa construção discursiva. 
| 88 |

Leci e Januário: escrevizências negras...

Garcia. Mãe e pai se encontram na capital de Minas Gerais e, juntos, formaram a família de classe média baixa. Dona Geralda trabalhava em casa, cuidando do lar e da família e seu Januário era funcionário público. Janu ficou órfão de pai com cinco anos e de mãe, com dez anos.

Januário é uma das principais lideranças orgânicas do Movimento Negro contemporâneo, além de ter sido um dos membros fundadores do Movimento Negro Unificado (MNU) e do Instituto de Pesquisas das Culturas Negras (IPCN). Possui formação e vivência no campo do cinema e, antes de atuar como fotógrafo profissional, na área de publicidade e imprensa, foi soldado paraquedista do Exército Brasileiro. As orientações da mãe serviram-lhe de luz que o conduziu, ainda nos anos 1970, ao trabalho de documentação visual, tanto dos momentos de articulação política e cultural do movimento negro $\left(\mathrm{MN}^{11}\right)$ brasileiro, quanto dos aspectos socioculturais da população negra e de grupos situados nos países do continente africano como Marrocos, Togo, Senegal, além de países da América Latina e Europa.

Alfabetizada em casa por dona Lecy ${ }^{12}$, Lecizinha sempre se destacou na vida escolar. Suas qualidades como escritora ainda na infância certamente contribuíram para sua vivência como compositora, para que se tornasse "jornalista musical", como se autodefine (cf. SOUSA, p. 86). Ao concluir o ensino primário, hoje fundamental $\mathrm{I}$, Lecizinha ingressou numa das escolas públicas mais tradicionais e elitizadas do Rio de Janeiro, o Colégio Pedro II. Ainda que tenha percebido as especificidades de seu próprio cor/po, muito distinto do das outras alunas,

\footnotetext{
${ }^{11}$ De acordo com o sociólogo Amauri Pereira (2008), é a partir da década de 1970 em instituições políticas constituídas por militantes negros (mulheres e homens) que a expressão MN passa a ser comum para identificar as ações dessas entidades. A expressão caracteriza a reunião de diferentes segmentos da sociedade organizada, que têm como causa principal o combate ao racismo, além do reconhecimento e valorização da cultura negra.

${ }^{12}$ Lecy com “y” distingue mãe da filha, Leci. O mesmo se dá com 'Lecizinha'.
} 
e que tenha sentido as piadas racistas dos colegas de sala, a única menina negra da turma, moradora do subúrbio, integrouse socialmente no colégio também por via musical. Ao parodiar uma música marcante do surgimento da jovem guarda, a versão brasileira de "I'm in love", de H. Earnhart, assinada por Renato Corte Real, "Broto legal", que fazia muito sucesso na época na voz de Sergio Murillo, Leci ficou conhecida por bolar a letra que elegeu a chapa Pedro II para o Grêmio estudantil (cf. SOUSA, 2016, p. 656).

Dos 11 aos 16 anos, Januário Garcia viveu nas ruas da cidade do Rio de Janeiro, onde dormia sem cama fixa debaixo de marquises. A formação herdada de sua mãe possibilitou ao adolescente enfrentar as adversidades e perigos das ruas. Por cinco anos, ele tomou banho com água apanhada de chafariz; comeu o que ganhava dos feirantes ou do que comprava com os cruzeiros que conquistava como engraxate. Ele conta que viver na rua foi difícil e, durante esse período, pôde refletir sobre a importância da educação, dos valores passados em seu núcleo familiar:

[...] eu sempre achava que eu não podia fazer nada errado, porque a minha mãe sempre dizia que eu não deveria fazer coisa errada. [...] Então, esse norte que a minha mãe me deu foi o que me balizou na rua. Eu não podia fazer nada ilícito! Porque a minha mãe não ensinou a gente a fazer nada ilícito. [...] Viver na rua era um negócio muito difícil, porque você estava sujeito a todo tipo de violência. Sujeito a todo tipo de discriminação. Sujeito a todo tipo de exclusão. Era um negócio muito sério ${ }^{13}$. ${ }^{13}$ Cf. Januário Garcia. Entrevista a Vilma Neres Bispo, 2 áudio digital TASCAM
(2h27min.), Rio de Janeiro/RJ, 10 out. 2014. 
|90|

Leci e Januário: escrevizências negras...

Desde cedo, "a filha da dona Lecy"14 experienciou práticas religiosas. Na infância, teve contato com o universo religioso católico por influência de sua madrinha Estelinha, mas foi a cosmovisão de matriz afro-brasileira que permeou sua vida e carreira. A partir da vivência nos terreiros de umbanda e candomblé, a artista forjou sua sonoridade:

[...] em dias frios, as pessoas ficavam no terreiro e dormiam lá. Sua mãe vestia um pijama, ela fazia o mesmo, sendo que havia um lugar separado para as crianças dormirem. Leci, no entanto, não dormia, ficava observando as pessoas tocarem. Conta que teve então um dia que alguém faltou e ela disse "deixa que eu toco". Começou então a aprender a tocar tambor no centro de umbanda. $\mathrm{O}$ tantã que toca hoje em seus shows foi, portanto, algo que veio dos aprendizados adquiridos na vida religiosa (SOUSA, 2016, p. 80).

O entendimento que Leci faz de si mesma como artista que forja composições está estreitamente ligado às experiências no universo dos orixás. Para ela, compor é como estar numa espécie de transe, pois ainda que nem tudo que escreva diz de si mesma, tudo passa por sua forma de entender e sentir as coisas e o mundo. A vivência marcada pela cosmovisão negra afrobrasileira ficou explícita em 1980, quando passa a gravar canções homenagens aos orixás, somando-se a outros artistas que realizam escre(vivências) do universo religioso por via da canção popular (cf. idem, p. 85-85). Sua vida pessoal é regida por Ogum e Iansã, sendo o primeiro seu orixá de cabeça. Embora saibamos que a relação entre o pensamento do artista e a forma da obra nunca são simples e imediatas (cf. GARCIA, W., 2013b, p. 87), podemos

\footnotetext{
14 Título de uma das canções que Leci compôs em homenagem à sua mãe. Também intitula o estudo da trajetória de Leci realizado por Fernanda Kalianny Martins Souza (2016), que embasa a maior parte das informações contidas neste trabalho.
} 
estabelecer algumas relações entre a fala que a artista compõe de si mesma e o que ela expressa em suas composições.

Durante a infância em Minas, Januário guarda memórias do fascínio pela imagem que descobriu em contato com alguns exemplares da revista Tico-Tico ${ }^{15}$ e ao manipular películas de filme cinematográfico. Ele aprendeu a montar um projetor com lâmpada incandescente e caixa em madeira, brincadeira que lhe despertou a criatividade. Os pedaços de película retiradas do lixo da única sala de cinema, sala que ficava próxima à sua casa, formavam fotogramas de filme cinematográfico. Ele recolhia os fotogramas e os projetava no quintal de sua casa. As projeções eram realizadas sempre à noite e ele criava e narrava as estórias conforme a leitura que ele próprio fazia das imagens.

Januário produziu seu primeiro filme de animação com fotogramas de película, pintados com pena de peru e tinta de urucum. A produção desse filme aconteceu por intuição e acaso, depois de ter esquecido uma tira de película no bolso da bermuda que a mãe lavava junto com outras peças de roupas. Durante a lavagem, a emulsão soltou, deixando a celulose lisa. Depois disso, começa a criar ilustrações e pintá-las quadro a quadro inventando, com a ajuda de sua irmã caçula, muitas estórias animadas projetadas à noite para o público, seus colegas de infância.

Além da musicalidade expressa e sentida através da religiosidade, Leci foi muito influenciada por seu pai, que gostava de ouvir desde ópera a chorinho e comprava discos de $78 \mathrm{rpm}$ sempre apresentando novos artistas à filha. Essa relação com o disco é muito relevante para artistas hoje consagrados, mas que têm origens periféricas. De maneira semelhante,

\footnotetext{
15 Segundo o banco de dados digitais da Biblioteca Nacional, a revista Tico-Tico influenciou gerações de 1905 a 1962 e era direcionada ao público infanto-juvenil. Elaborada pelo jornalista Luís Bartolomeu de Souza e Silva, a publicação reproduziu charges e ilustrações de cunho racista contribuindo para o caráter racista de, ao menos, quatro gerações consecutivas. Para saber mais, ver: Oliveira Neto (2015).
} 
|92|

Leci e Januário: escrevizências negras...

o universo da fotografia era inacessível às populações empobrecidas e grupos negros.

Dos 1950 aos 90, o campo musical quase obrigava os artistas a filiarem-se às gravadoras para ter impacto no mercado e obter (re)conhecimento público (cf. SANTOS, 2014b). Tendo em vista que a indústria fonográfica foi um espaço de acesso restrito a determinados grupos sociais, tanto para gravar discos quanto para consumir canções (cf. idem), posar para uma foto e produzir para capas de discos é ainda mais significativo para pessoas negras. Dessa forma, as ausências tornam-se presenças relevantes expressas na atuação de fotógrafos como Januário Garcia ${ }^{16}$, dedicando-se a escrever com a luz a história de outras pessoas, buscando mudança de paradigmas para as relações étnico-raciais no Brasil.

Os atributos guerreiros fazem de Leci conhecida também por seu engajamento político na tessitura poética de suas canções. Assim, ela "tem talento" e "dá sentido a tudo que faz" de modo que possa caminhar enquanto mulher negra para garantir seu lugar ${ }^{17}$ na cena artística emplacando músicas de sucesso ${ }^{18}$, mas também em outros espaços, como a legislatura ${ }^{19}$.

\footnotetext{
${ }^{16}$ Mas também de fotógrafas como Lita Cerqueira, que vem contribuindo para a memória social de pessoas negras ao vincular a questão profissional com o aspecto social e étnico-racial. Sobre a trajetória de Lita ver: Bispo (2016).

${ }^{17}$ Verso final da faixa-título do LP Essa tal criatura.

${ }^{18} \mathrm{O}$ engajamento político de Leci a teria feito uma artista cujo público consumidor pertencia às classes sociais intelectualizadas. O caráter mais popular de sua obra teria mudado após o disco Leci Brandão pela gravadora Copacabana em 1985 (cf. SOUSA, 2016, p. 98).

${ }^{19}$ Leci foi membro do Conselho Nacional de Promoção da Igualdade Racial e do Conselho Nacional dos Direitos da Mulher. Em 2010, eleita deputada estadual de São Paulo pelo Partido Comunista do Brasil tornando-se segunda mulher negra a ocupar o parlamento paulista; reeleita em 2014. Dedicou-se às religiões de matrizes africanas, populações negras e indígenas, juventude, mulheres e mulheres negras, segmento LGBTT e cidadania, universo do samba e assuntos relacionados à mobilidade urbana e transporte público. Na Assembleia do Rio, destacou-se à Comissão de Educação e Cultura e à Comissão de Direitos Humanos. Como presidente da Frente Parlamentar em
} 
Conforme atesta sua ampla discografia, bem como os vários prêmios que recebeu, entre eles: finalista do Prêmio Shell de $M P B$ na Rede Globo com o LP Essa tal criatura, em 1980, participando do Word Popular Song Festival no Japão, e vencendo o Prêmio Sharp em 1995 e 2008, com o LP Anjos da guarda e com o CD $E u$ e o samba, seu trabalho encontrou amplo reconhecimento de público e de crítica.

O teor político crítico contemporâneo das letras das canções de Leci implica em enfrentamentos com a indústria fonográfica, que culminaram em firmes escolhas feitas para direcionar sua própria carreira. Em depoimento transcrito por Fernanda Sousa (2016), Leci relata seu rompimento com a gravadora Polygram, fato que a retirou do mercado fonográfico de 1981 a 1985. A artista volta a gravar pela Copacabana, um ano depois de retornar de Angola, numa viagem feita em 1984 a convite de Martinho da Vila:

\begin{abstract}
Minha saída da Polygram se deu porque não aceitavam meu repertório em geral, disseram que tinha muita música política. Achavam que eu tinha um trabalho muito pesado em termos de letra, era muito contestadora, era muito preconceito sendo questionado. Falaram que eu tinha que fazer um outro som, que era para eu ir para casa e pensar em fazer outro tipo de música [...]. Cheguei em casa, peguei a máquina de escrever, peguei uma folha e fiz uma cartinha, dizendo que não queria mais continuar. Pedi rescisão de uma multinacional, ninguém faz isso e eu fiz (apud SOUSA, 2016, p. 98).
\end{abstract}

Defesa da Cultura em São Paulo, atuou de forma propositiva como frente ao Projeto Cultura Viva. Na questão da igualdade racial, avançou a discussão sobre as cotas nas universidades públicas em São Paulo e apresentou o Projeto de Resolução 01/2013, que institui o Prêmio Doutora Theodosina Ribeiro, para destacar a ação de mulheres e organizações voltadas às mulheres negras. Conseguiu a aprovação da Lei 15.082/2013, que amplia a rede de atendimento às vítimas de homofobia em São Paulo. Disponível em: <https://www.al.sp. gov.br/alesp/deputado/?matricula=300513 . . Acesso em: 26/10/2016. 
|94|

Leci e Januário: escrevizências negras...

Do episódio narrado por Leci pode-se perceber que os parâmetros exigidos pela indústria fonográfica não estão conectados com os anseios e concepções artísticas da realizadora. As produções de suas narrativas cancionais adquirem sentidos próprios, conduzidos pela autora, constituindo marcadores de classe, gênero e etnicidades, ainda que essas imagens sejam utilizadas para propagação de um produto comercial.

Interessante notar que foi justamente a propaganda que aproximou os caminhos de Leci e Januário, já que o encontro para a realização das capas da compositora se deu a convite do diretor de criação da Polygram em meio aos trabalhos que Januário realizava na MPM, importante agência de publicidade brasileira. Por outro lado, não podemos esquecer de que a propaganda constitui-se como lugar de produção de potentes discursos ideológicos com longo alcance nas sociedades contemporâneas. Por conseguinte, para as pretensões deste trabalho, privilegiamos o campo artístico como lugar onde são produzidos sentimentos que nos humanizam, para além da esfera lucrativa e exploratória. O cotejo das obras como narrativas específicas (cf. GARCIA, W., 2013a), isto é, enquanto textos musicais e fotográficos, permite situar Leci Brandão e Januário Garcia em suas trajetórias, construídas a partir da identidade étnico-racial e de gênero no campo da música artístico durante o século XX.

Para isso, tomamos como referência as fotografias, de Leci, feitas por Januário Garcia para compor as capas de Coisas do meu pessoal e Essa tal criatura. Selecionamos versos das letras que compõem os álbuns, com destaque para o primeiro, tendo em vista que tanto um quanto o outro, surgem num período em que a música popular brasileira constitui espaço fundamental para o debate social de temas como gênero, por via do feminismo e identidade negra, sob o prisma étnico-racial (cf. PEREIRA, 2010), sendo o disco o veículo com maior visibilidade e difusão do que as produções realizadas no ambiente acadêmico-universitário. 
(foto)escre(vivências) e artivismo antirracista: duas capas de Leci (1977-1980)

Afinal, a poética cancional de Leci e a luminosidade de Januário podem ser vistas como escritas, em que a compositora e o fotógrafo compõem sobre si mesmos e sobre o mundo. Compreendemos ambas narrativas e trajetórias como escrevizências, conceito de Conceição Evaristo (2003; 2008), Buscamos os três eixos fundamentais propostos pela autora: corpo, condição e experiência. A corporeidade funciona como porto seguro de afirmação dos traços identitários em contraponto aos estereótipos. O segundo eixo concentra a condição do sujeito negro, a tomada de consciência étnico-racial. O terceiro diz respeito às experiências do sujeito negro no curso histórico-social e na construção de redes de solidariedade.

Tal como Leci, a obra de Januário aparece como escrevizência, mas na forma de (foto)escre(vivências) (cf. BISPO, 2016). Trata-se das fotos como escrita com a luz que possibilita narrar sobre o que é visível ao olho humano. A produção da escrita com a luz é uma construção social, tal como o uso que se faz dela. No artivismo antirracista não se constroem representações imagéticas que reforcem estereótipos raciais e estigmas sociais. O objetivo é realizar abordagens críticas e criativas em busca de modos alternativos de ver o mundo e de humanizar o Outro. Como Azoilda Loretto da Trindade (2013, p. 16) observa, o racismo não é natural, não é intrínseco ao ser humano, às pessoas. Aprendemos a ser racistas, a (re)produzir o racismo. Sendo assim, também podemos aprender a não ser racistas (cf. TRINDADE, 2005, p. 51).

Escrevizência entendida, aqui, como imagem e/ou poética, constitui-se como ferramenta discursiva e refere-se a quem se debruça em compor, apresentar e defender repertórios que possam provocar reflexões acerca da produção artística de/sobre pessoas negras, tal qual se percebe o ser humano como o ser-sujeito negro é. Os recursos imagéticos e poéticos, além de romperem com silêncios e proporem mudanças em torno 
|96|

Leci e Januário: escrevizências negras...

da representação visual e musical, permitem mobilizar discursos estéticos de artivismo antirracista no campo artístico e político das relações étnico-raciais e de gênero, ao referenciar os diferentes modos de ser, agir e estar no mundo. Tanto em Leci quanto em Januário temos escrevizências negras.

Desde o princípio, eu sempre vislumbrei a possibilidade de que essas fotos, que eu estava fazendo, fossem contribuir, de uma maneira ou de outra, para contar a história de um tempo; é a história de um tempo importante na sociedade brasileira, que foi a retomada da luta negra no Brasil, numa luta contra o racismo e contra a ditadura, [porque] [...] as coisas caminhavam juntas. Então, eu sempre vi a possibilidade de documentar esses momentos como momentos que pudessem no futuro, não só, fazer parte de um relato escrito, mas também com imagem ${ }^{20}$.

Escrevizências negras inspiram e permitem pensar a construção de discursos visuais fotográficos, poéticos e musicais como instrumentos políticos que possam reivindicar, reconhecer e expressar a diversidade de gênero e identidades étnico-raciais específicas. Tal movimento acontece nos versos de Leci:

Se a gente ainda tem uma chance/ De sair pra passear/ Então vamos ao teatro/ Acho o melhor lugar/ Para encontrar/ Para abraçar/ Nossos amigos/ Que ainda podem/ Nos representar/ Em cada ato/ Uma verdade/ Que cada ator/ Nos aponta/ A gente encontra a realidade/ Que aqui fora/ Nem deu conta/ E aquele palco/ Tão estranho/ Limitou nosso cantar/ Não por culpa de tamanho/ Sim/ Por medo do falar/ Mas o elenco/ Sempre atento/ Sobrevive/ E ainda pode/ Nos representar.

\footnotetext{
${ }^{20}$ Cf. Januário Garcia. Entrevista a Vilma Neres Bispo, 2 áudio digital TASCAM..., op. cit.
} 
Os versos de "Vamos ao teatro" remetem imediatamente, mas também de modo metafórico, ao campo artístico como campo político: cada ato vivido no palco revela uma verdade nem sempre percebida no âmbito da realidade cotidiana. Assim, o meio artístico torna-se meio de vivência e de escre(vivência), quando resulta em amplo espaço de lutas e fonte, na qual bebem os próprios artistas e intelectuais militantes da sociedade no período em que teve lugar a canção. Outra leitura possível remete à vivência da compositora, no início da década de 1970, junto ao Grupo Opinião, espaço cultural relevante por fazer frente ao regime militar e realizar debates artísticos de protesto.

Quando consideramos a cor/poralidade da compositora e o nome do disco no qual a canção foi gravada, Leci revela seu lugar de fala. "Vamos ao teatro" é faixa do disco Coisas do meu pessoal (1977), que celebra o campo artístico como palco de militância social nos anos 1960/70, não apenas contra a ditadura militar, mas também como frente ampla de lutas antirracistas, de identidade étnico-racial e de gênero. Pouco se fala da presença e atuação de mulheres negras como dona Ivone Lara e Leci Brandão no universo do Teatro Opinião nos anos 1970 (cf. SOUSA, 2016, p. 95). A canção expressa, portanto, um discurso de metalinguagem, sintetizando amplo diálogo com a realidade histórica de fins dos 60 e início de 70, resultando na constituição de histórias e geografias poéticas, potentes imagens cancionais e atributos de memória social.

Logo, o contexto histórico-social e cultural é alicerce dos processos de construção das imagens poéticas e imagéticas. Quando pensamos que as artes constituem, historicamente, um lugar das lutas negras antirracistas por excelência, já que a cosmovisão afro-brasileira implica necessariamente na arte como campo político, religioso e como construção de saberes sociais, o chamado para "ir ao teatro" não pode ser reduzido ao mero entretenimento, ainda mais no contexto do regime militar. Trata-se de chamado combativo à própria classe artística cujo "elenco, sempre atento, sobrevive", ao produzir discursos e narrativas (imagéticas, cancionais, teatrais, visuais, literárias, 
|98|

Leci e Januário: escrevizências negras...

sonoras, religiosas, plásticas, entre outras) que produzam contra-representação, gerando e fomentando novas e amplas formas de conhecimento. É, em suma, remeter à própria trajetória de Leci, mas também de Januário.

A oposição entre lentes convexas e côncavas - luz para dentro, de modo a propagar a imagem de forma invertida e, a segunda, permitindo efeito contrário - é metáfora que nos ajuda a pensar os usos e sentidos da imagem do sersujeito negro produzido por seus pares para ver Januário atuando organicamente junto à coletividade, como resultado de uma luta anterior, de muitas pessoas. Ele se entende "como negro brasileiro, não como aquele negro que sei onde é o meu lugar, porque o meu lugar não existe. $\mathrm{O}$ meu lugar é onde eu estou! Já é, aqui e agora! 'O lugar é aqui e agora', como diz o Gil”21.

Tanto Leci quanto Januário passaram por processos importantes que ajudam na compreensão do desenvolvimento da indústria fonográfica e fotográfica no Brasil. Faz-se relevante discutir a produção discográfica de artistas negros brasileiros, para pensar a forma disco além da esfera meramente comercial, encarando-a como materialização de processos de subjetivação e conotação das trajetórias individuais e coletivas. Deste ponto em diante, discutimos a produção de dois discos de Leci, Coisas do meu pessoal (1977) e Essa tal criatura (1980).

A fim de problematizar nossos objetivos, pensamos a forma disco enquanto produto-síntese que concentra diversas facetas, entre as que importam para essa discussão, a expressão de subjetividades dos artistas realizadores, pois a estética do LP para além da canção (melodia e letra) implica também na construção de imagem fotográfica que atue como síntese da mensagem geral da produção discográfica.

Dentre os diversos encontros celebrados na produção de um disco, estão aqueles que marcam a compositora-intérprete e o fotógrafo de capa, ambos empenhados em criar uma representação cor/pórea e estética da artista, que diga algo de suas

${ }^{21}$ Cf. idem, ibidem. 
peculiaridades individuais e, no campo artístico, que seja sugestivo dos sentidos produzidos através/por meio de pistas que geraram as canções gravadas. Leci Brandão, ao ser fotografada por Januário para as capas dos discos, deixa-se captar poética e subjetivamente pelo olhar do outro, mas também do semelhante.

FIGURA 1 - Leci Brandão por Januário Garcia. LP Coisas do meu pessoal. Polydor/Polygram, 1977.

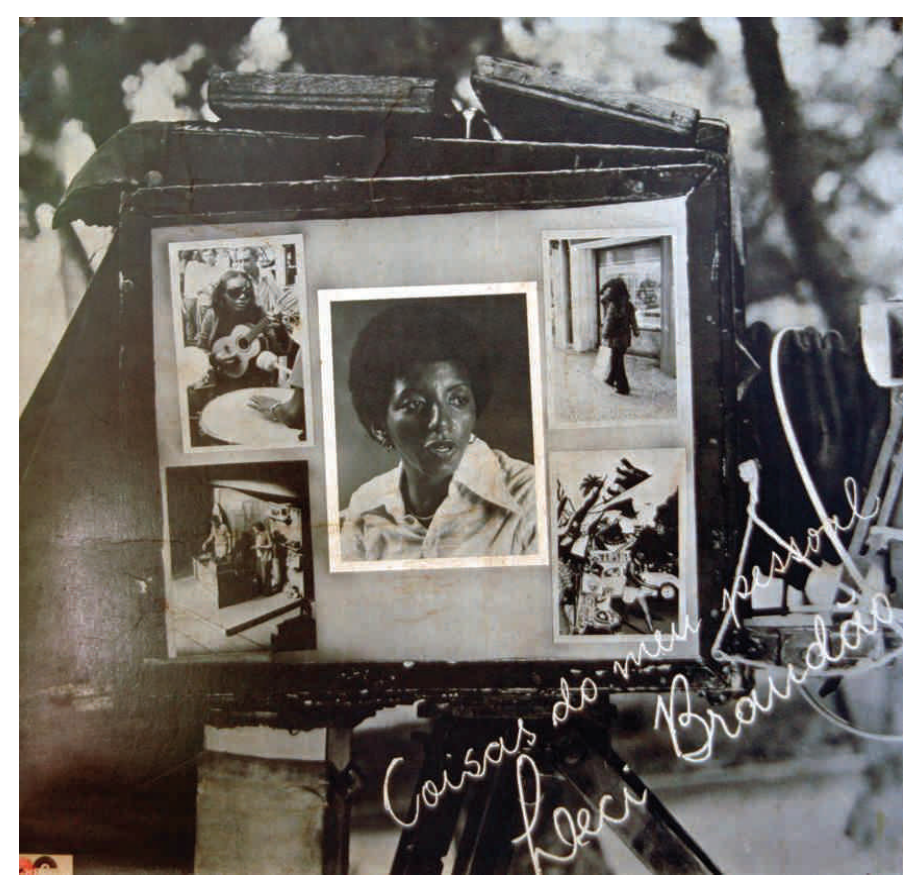

A capa do disco Coisas do meu pessoal (fig. 1), produzida em 1977 por Januário Garcia, apresenta seis imagens fotográficas, isto é, uma imagem que incorpora outras cinco e que, em conjunto, propõem narrativa visual de metalinguagem. As cinco imagens estão dispostas em primeiro plano e, em segundo 
$|100|$

Leci e Januário: escrevizências negras...

plano, observamos uma câmera laboratório, um lambe-lambe ${ }^{22}$. A composição fotográfica dessa imagem que, literalmente, embala a capa do disco, expressa signos que conotam um espelho repleto de memórias negras. Segundo Januário, a capa buscou pensar as "coisas do meu pessoal" de Leci como música de alcance popular, que circule na rua. Januário trouxe a questão do lambelambe justamente por seu caráter de fotografia popular, laboratório que se monta nas praças; forma de fotografia acessível a amplos públicos.

Historicamente, antes da segunda metade do século XX, são pouco difundidos os registros fotográficos marcantes da contra-representação negra. Desta forma, o movimento de representatividade orgânica realizado por Leci e Januário, dentre outros artistas em fins dos anos 1960 e decorrer da década de 1970, viabiliza e difunde narrativas próprias dos grupos e pessoas negras. No caso das capas de Leci, a concepção de Januário promove e inspira os temas refletidos nas letras cancionais da artista e de sua personalidade, reportando, reconhecendo e valorizando as coisas do seu pessoal e, ainda que o universo autoral de Leci não esteja restrito ao samba como gênero musical, tais fotografias dialogam com a cosmovisão negra afro-brasileira, que é muito marcada pela musicalidade. As canções desse álbum atuam como meio de expressão potente para definir aspectos socioculturais e políticos como, por exemplo, a articulação de pessoas e grupos envolvidos numa escola de samba frente ao racismo, ao mesmo tempo em que apontam os processos

\footnotetext{
${ }^{22}$ A câmera laboratório, conhecida também por câmera escura, tem esse nome por se tratar de um mecanismo tradicional que fixa a imagem diretamente sobre um papel fotográfico e que também dispõe de recipientes com revelador e fixador, produtos químicos necessários para a revelação. A câmera laboratório vem acoplada dentro de uma caixa de madeira coberta por um tecido na cor preta. E essa caixa é presa num tripé, o que permite certa mobilidade ao fotógrafo ao perambular pelos espaços públicos em busca de pessoas que desejam ter a sua imagem fixada imediatamente e sob o olhar de transeuntes.
} 
de exploração capitalista que supostamente as desagregam, conforme se notam nas canções "Apenas um bloco de sujo" e "Marias".

"Formar um bloco de sujo" para sambar, a fim de realizar enfrentamento às transformações dos desfiles do carnaval carioca na década de 1970, é o mote principal da primeira narrativa: "O pessoal lá do morro resolveu/ Formar um bloco de sujo pra sambar/ Porque a escola enriqueceu, e a gente nossa já não tem lugar". Os processos de injeção de capital e promoção exterior ocorrem "quando aparece um 'cidadão' externo à vida cotidiana da comunidade do samba e, repentinamente, assume a direção de harmonia da Escola". Processos de embranquecimento dos cor/pos dos destaques surgem quando "a loura manequim, de jeito diferente puxará, a comissão de frente". A poética da narrativa aponta para a intensificação dos processos de re-produção capitalista articulada à organização das agremiações e à padronização dos cor/pos dos sujeitos-brincantes no prisma da branquitude, fazendo com que, nas escolas de samba, já não tenha "lugar" a "gente nossa".

Em contraste com o que mencionamos antes, o mesmo samba infere: “Tião, nosso primeiro ritmista, nunca recebeu uma homenagem/ e Conceição, aquela negra passista, foi cortada por não ter, imagem". A memória de lutas de grupos negros contra o racismo e apropriação cultural de seus saberes e práticas, por grupos alienígenas, confronta: "O pessoal, por estas razões, tomou as decisões: um bloco de sujo sem promoções".

Como se nota, "Apenas um bloco de Sujo" construindo narrativa oficial dos processos vivenciados no samba, a partir da ótica dos grupos envolvidos nos processos, expressa um retrato falado da realidade desses sujeitos partindo das tensões que permeiam suas relações sociais e étnico-raciais, tornando o samba prática poética de re-produção de conhecimentos sobre a população negra na cidade, contribuindo para historicizar o Carnaval do Rio de Janeiro em fins do século XX, resultando 
| 102 |

Leci e Januário: escrevivências negras...

numa forma singular e histórica de escrevizência (cf. EVARISTO, 2003, 2008).

Retomando a capa do álbum no sentido de escrevizência, pode-se dizer que ela remete ainda ao próprio Januário como fotógrafo lambe-lambe, ao compor, criativamente, um espectro de imagens que vão revelando Leci: suas coisas pessoais e do seu pessoal, tal como a tinta e a tessitura de imagens em movimento que Janu montou ainda criança, ao inventar suas estórias/histórias com pedaços dos filmes descartados pelo cinema em $\mathrm{BH}$.

Na sequência da audição do disco, a canção "Marias" expressa um continuum narrativo crítico em tom de crônica, apontando a dicotomia específica imposta pela geografia social da cidade do Rio de Janeiro da segunda metade da década de 1970, cuja configuração ainda é atual. Na poética de "Marias", Leci entoa: "Maria da cidade anda bem vestida/ Maria do subúrbio não sabe de moda/ Maria da cidade vive a boa vida/ Maria do subúrbio faz da vida roda/Maria da cidade tem boa empregada/ Maria do subúrbio tem que se empregar/ Lavando cozinhando e arrumando a mesa/ Pois dinheiro da despesa tem que se poupar/ Laialá" [...], para sobreviver no Rio de Janeiro do século XX.

A canção tem início e termina com 'laialá', sentido pela com-positora e intérprete, expressando o lamento de alguém cujo cor/po ocupa lugar socialmente determinado. Tais lamentos expressam constatação da realidade e, justamente por isso, implicam numa necessária transformação social, via percepção e conscientização das tensões impostas pela normatividade. A voz ativa de mulher negra pensando sobre a geopolítica da cidade desnuda conflitos de raça e classe entre mulheres negras e brancas, empregadas e patroas na zona sul carioca. Ainda que retome o universo cancional de "Cadê Mariza", aqui já contemplado, do primeiro compacto de Leci, Mariza também se confunde e retoma Conceição, passista de "Apenas um bloco de sujo", com a diferença de que Mariza buscou a projeção de sua imagem na mídia hegemônica ao custo de ausência 
na agremiação, enquanto Conceição permaneceu na escola, mas foi excluída da projeção do desfile midiático por não ajustar o cor/po a tal imagem. Tais operações explicitam facetas veladas dos processos de empobrecimento, do machismo e do racismo crivados por questões de gênero na contemporaneidade.

FIGURA 2 - Leci Brandão por Januário Garcia. LP Essa tal criatura. Polydor/Polygram, 1980.

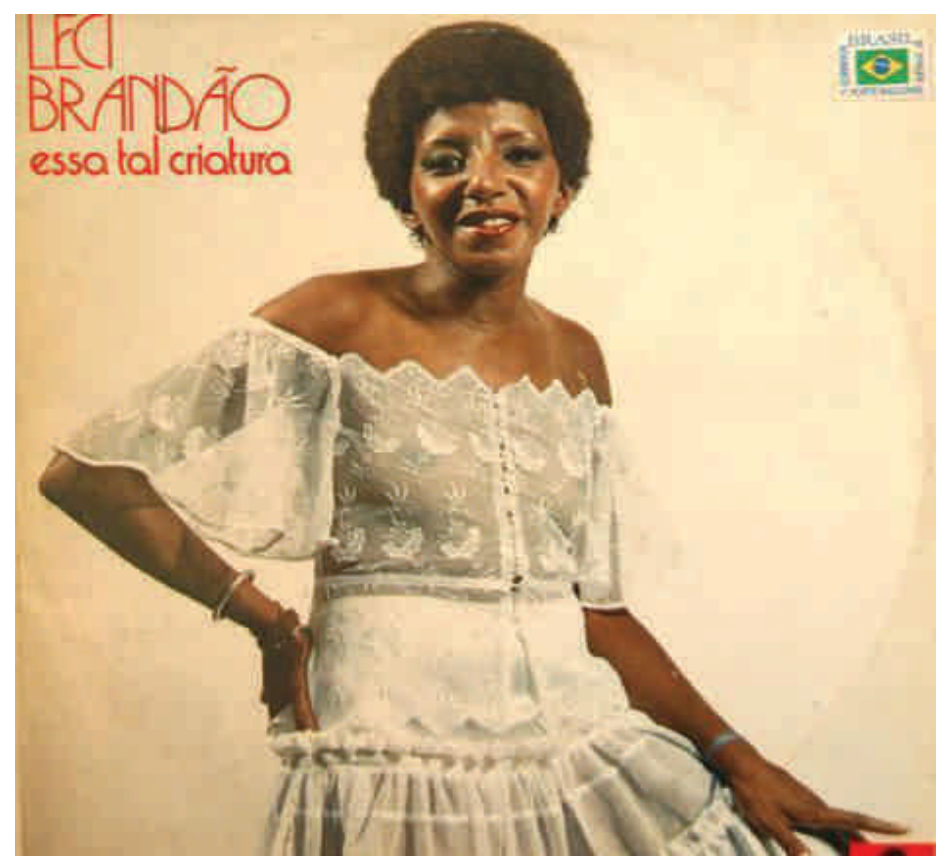

Do ponto de vista étnico-racial entremeando as trajetórias das personagens está o racismo: Conceição é a "negra passista", enquanto Mariza "era uma morena". Percebe-se que a própria lógica cancional e poética de Leci é auto-referencial, tanto na esfera ficcional quanto no âmbito da realidade, permeando diferentes 
| 104 |

Leci e Januário: escrevizências negras...

álbuns e assumindo distintos aspectos de uma mesma temática ou de temáticas entrecruzadas.

A imagem (fig. 2) ilustra a capa do sétimo álbum de Leci Brandão, de 1980. Ela sorri timidamente e, como se quisesse dispensar um requebrado para o lado, parece estar de pé, porém com a perna esquerda levemente apoiada em algo, com o braço direito curvado sobre os quadris e o outro braço se apoia sobre a perna esquerda. Usa pulseiras nos punhos e um par de pequenas argolas nas orelhas. O seu rosto exibe a aplicação de maquiagem, como sombra nas pálpebras, batom nos lábios, rímel nos cílios e as bochechas foram acentuadas com blush. Veste uma bata rendada na cor branca e transparente, pois, é possível visualizar os seios. Além disso, ela veste uma saia rodada, também na cor branca.

Tanto a escrita com a luz quanto a produção desta imagem foram elaboradas pelo fotógrafo Januário Garcia, pois, foi dele a ideia de a cantora retirar o sutiã, numa tentativa de refletir o tema do álbum Essa tal criatura, cuja canção homônima diz: “Tire essa roupa/ Pisa na terra/ Rasgue essa roupa/ Mostra teu corpo/Seja essa cara/Sinta meu gosto/ [...] Ama na maior liberdade/ Abra, escancara esse peito/ Clama!/ Só é linda a verdade/ Nua sem ser preconceito [...]". No verso final da canção, a afirmação de duplo sentido ganha potencial de protesto e enfrentamento de questões silenciadas como o racismo e o relacionamento homoafetivo:

[...] rasga essa roupa, mostra teu corpo/ [...] Morda uma fruta madura/ Lamba esse dedo melado/ Transa na mais linda loucura/ Deixa a vergonha de lado/ [...] Ama na maior liberdade/ Abra, escancara esse peito/ Faça da vergonha loucura/ Abra, escancara a verdade/ [...] Só é linda a verdade, nua, sem ser preconceito/ [...] Sinta esse tombo/ Rala esse rosto/ Transa com a lua/ Morda essa cara/ Linda, tão nua, faça da vergonha loucura/ Abra, escancara a verdade/ Ama essa tal criatura que envergonhou a cidade. 
Além de outras questões, essa composição aborda o tema de liberdade; a liberdade do corpo do ser-sujeito negro. Retomando a análise dessa capa (fig. 2), verifica-se que o fotógrafo produziu a imagem em um estúdio e, certamente, pôde utilizar o recurso da luz artificial, a exemplo de flash nas laterais e, possivelmente, luz de enchimento, muito utilizada para diminuir o contraste entre as cores. O tipo desta imagem é pousado, identificado na encenação física da cantora. A vestimenta, e também pela maneira como Leci ampara as suas mãos, nos remete ao arquétipo comportamental de uma "baiana", construído no imaginário social brasileiro, sobretudo através da música. Como exemplo, a composição "Conceição da Praia", de Luiz Carlos Máximo, que traz o seguinte trecho: “[...] Tem baiana formosa de bata rendada; de brincos de ouro e sandália enfeitada; como requebra bem; quem me dera/ $\mathrm{Ai}$, se eu pudesse ir à Conceição também [...]" numa referência ambivalente entre mulher e santa, remetendo aos universos sagrado e profano.

"Fotografar alguém é roubar seu dyaa $a^{23 "}$, conforme nos conta Youssouf Tata Cissé (cf. KEÏTA, 2014, s/p.) ao ouvir de uma senhora Malinke que o soberano Somari Touré (1830-1900) só foi derrotado por ter sido fotografado pelos franceses, tendo seu "espírito ativo" roubado. Segundo o antropólogo, essa crença é ainda disseminada entre pessoas de mais idade por resistirem ao ato fotográfico, sobretudo se for operado por pessoas desconhecidas. Essas pessoas se preocupam com a autoimagem e, portanto, são cuidadosas por não saberem como o uso das imagens de si poderá impactar determinadas perspectivas que, por vezes, fogem do controle das pessoas fotografadas.

Seguramente, essa é uma crença histórico-filosófica interessante para aprofundar a compreensão acerca do discurso da (foto)escre(vivência). Tal discurso envolve percepção técnica,

${ }^{23} \mathrm{O}$ termo "dyaa" é utilizado na cultura Malinke para denominar diferentes sentidos: "duplo vital", "espírito ativo", "inteligência", "reflexo", "atenção", "sombra", "imagem". 
|106 |

Leci e Januário: escrevizências negras...

política e crítica do contexto histórico-social, além de senso estético para dirigir a distribuição da luz que ilumina o objeto, e/ou a pessoa em foco. Além de ser resultado do modo de perceber e avaliar o mundo conforme o olhar da fotógrafa ou do fotógrafo, as imagens produzidas para as capas de disco exigem um cuidado especial. Januário observa que é necessário estar enturmado com a/o artista, perceber seu estado de espírito e a proposta artística para criar uma imagem que resulte na 'cara do disco'. A fotografia vai "embalar" o que a/o artista tem de melhor no momento de produção daquele álbum. Para Leci, Janu produziu cerca de seis a sete capas.

É sob tal perspectiva que refletimos a respeito das (escre) vivências sociais de Leci Brandão e Januário Garcia, conscientes de si. Com isso, vislumbra-se a compreensão da produção artística no sentido da contra-representação às imagens de controle e (auto) representação de seus pares, em igual condição de sujeito negro. É importante salientar que o "si" extrapola a noção de um eu individualizado e particularista para dar lugar a um eu coletivo que se constitui pela experiência compartilhada de uma história social, de uma cultura, de uma espiritualidade de matriz afrocentrada.

\section{Focos e versos finais}

Deixar-se fotografar é permitir que a imagem de si seja dominada, no sentido de permanecer à mercê de quem fotografa. $\mathrm{O}$ ato fotográfico, enquanto "reprodutibilidade técnica", é, também, "a percepção humana condicionada ao processo histórico" (BENJAMIN, 1987, p. 174). A fotografia não está limitada à reprodução da imagem, pois é texto visual que envolve a relação que o fotógrafo/a constrói com a pessoa fotografada e com todos os aspectos do entorno, sendo esses discursivos e visíveis. Quando admitida na forma disco, o discurso visual somase e vem completar a materialidade do discurso poético de quem compõe, toca e canta, aproximando e justapondo formas artísticas 
narrativas contempladas subjetiva e coletivamente, articulando memórias individuais e coletivas (cf. HALBWACHS, 2006).

O disco, como produto cultural, atua também como discurso escrito com a palavra cantada, em conjunto com o som e com a luz fotográfica, envolvendo percepção artística, técnica, política e crítica do contexto histórico-social, além de senso estético ao dirigir a distribuição da luz, que iluminará o objeto e/ou a pessoa em foco, seja pela crônica ou pela foto revelada. Este processo resulta ainda no modo de perceber e avaliar o mundo conforme o olhar dos artistas: Leci e Januário são reveladores da realidade dos cor/pos negros/as dispostos/as nas grandes cidades, numa leitura mais ampla dos discos aqui contemplados. Como artistas negros usam suportes e linguagens artísticas distintas, mas complementares e em relação, para dar materialidade à forma disco enquanto produto cultural e objeto de consumo. O fato é que essas formas de discurso, não apenas por questões estéticas, mas como potencializadoras de meios e lugares de memória, possibilitam argumento a ser debatido via recepção e, portanto, passível de crítica sociocultural.

É desse modo que o olhar do fotógrafo Januário Garcia constrói fragmentos de diferentes contextos do universo da cultura negra dentro e fora do Brasil. E como tal, fotógrafo profissional, ativista visual e militante político, a trajetória desse filho de Obaluaiyê e de Nanã que, como regem essas divindades, traz movimentos de decantação, de renovação e de evolução para a luta negra brasileira, sobretudo para as gerações seguintes de fotógrafas negras e de fotógrafos negros brasileiros.

Pensamos, então, nas fotografias de Januário Garcia que ilustram as capas de discos de Leci, bem como as escritas poéticas (letras) expressas em suas canções, como recursos da memória individual e coletiva capazes de conectar tempos na história e as pessoas deste tempo, sobretudo quando se trata dos povos negros nas Américas. Para nós, no Brasil, a memória fotográfica, narrativa, sonora e poética das pessoas negras pode imortalizar e reviver humanamente as alegrias, tal como as dores. Como escreve Sérgio Cabral na contracapa do disco de 1977, 
|108|

Leci e Januário: escrevizências negras...

abaixo da foto de Leci feita por Januário: "A compositora é também cronista, ao relatar os fatos de sua realidade e consolidando registros de sua época".

Essas trajetórias sociais transcorreram no auge da fotografia como dispositivo de registro informativo e documental, e quando da expansão do samba como música cujas narrativas atuam como construção identitária de compositores e intérpretes. Hoje, Leci e Januário acompanham as mudanças na produção musical e fotográfica: a música incrementada pelo samplers, tendo transformadas seus suportes e mídias, do long-play ao streaming e, no campo fotográfico, testemunham o processo de apropriação e popularização do discurso imagético.

Compreendemos as escre(vizências) como textos visuais e sonoros produzidos no curso da trajetória profissional e política de Leci Brandão e Januário Garcia. Em Leci e Januário, os atravessamentos musicais e imagéticos compõem escrevizências desde a infância. Os processos de musicalização em Leci, seja em casa por influência do pai, seja junto à mãe na vivência em terreiros de umbanda e candomblé, acompanharam também seu desenvolvimento escolar, haja vista a habilidade precoce em escrever, fundamental para o desenvolvimento das canções que vão sendo produzidas de forma autorreferencial das trajetórias individuais e de processos coletivos, coordenando denotação e conotação; e, em Januário, o aproveitamento criativo de filmes lançados ao lixo para a composição óptica (cinemato-fotográfica) foram ensinamentos que, junto às lições da mãe, perpetuaram-se efetivamente em suas memórias e vida pessoal, contribuindo para a atuação política no âmbito do Movimento Negro.

Ambos os artistas compõem discursos visual fotográfico e cancional-poético que podem funcionar como um (entre tantos) instrumento da luta antirracista - ainda que não precisem fazer isso o tempo inteiro, sobretudo pelo caráter disfuncional constituinte da criação artística - na medida em que carregam profunda conexão com os temas vividos de maneira experiencial, tanto no âmbito individual, quanto na dimensão coletiva e na medida em que dialogam com a realidade sociocultural 
e étnico-racial de um país extremamente racista e marcado pelas diferentes formas de colonialidade.

Por fim, cientes da necessidade de ruptura completa com as lógicas de colonialidade de saber, fazer e poder (cf. LANDER, 2005), buscamos perceber foto e música, bem como as trajetórias artísticas de Januário e Leci, como poéticas narrativas que apresentam potencial de discursos construtores de produtos que resultam em percepções de outras escrevizências, nas quais o "conhecimento" discursivo não constitui a representação do "real" na linguagem, mas consiste na articulação da linguagem em condições e relações sociais reais (cf. HALL, 2013, p. 434).

\section{Referências}

BENJAMIN, Walter. A obra de arte na era de sua reprodutibilidade. In: Magia e técnica, arte e política: ensaios sobre literatura e história da cultura. V. 1. 3ª̣ed. São Paulo: Brasiliense, 1987.

BISPO, Vilma Neres. Trajetórias e olhares não-convexos das fotoescre(vivências): condições de atuação e de (auto)representação de fotógrafas negras e de fotógrafos negros. Dissertação de Mestrado em Relações Étnico-raciais. Rio de Janeiro: Centro Federal de Educação Tecnológica "Celso Suckow da Fonseca", 2016.

EVARISTO, Conceição. Gênero e Etnia: uma escre(vivência) de dupla face, Texto apresentado na mesa de escritoras convidadas do Seminário Nacional $X$ Mulher e Literatura - I Seminário Internacional Mulher e Literatura, Universidade Federal da Paraíba, p. 1-15, 2003.

EVARISTO, Conceição. Escrevivências da afro-brasilidade: história e memória, Releitura, Belo Horizonte, Fundação Municipal de Cultura, n. 23, p. 1-17, nov. 2008. 
$\mid 110$ |

Leci e Januário: escrevizências negras...

GARCIA, Januário (org.). 25 anos 1980-2005: movimento negro no Brasil/ Concepção, organização e fotografia Januário Garcia. Brasília: Fundação Cultural Palmares, 2006.

GARCIA, Walter. Elementos para a crítica da estética do Racionais MC's (1990-2006), Idéias, Campinas, v. 4, n. 2 (7), 2º sem. $2013 a$.

GARCIA, Walter. Melancolias, Mercadorias: Dorival Caymmi, Chico Buarque, o pregão de rua e a canção popular-comercial no Brasil. Cotia: Ateliê, 2013b.

HALL, Stuart. Da Diáspora: identidades e mediações culturais. Belo Horizonte: Ed. UFMG, 2013.

KEÏTA, Seydou. Texto: Youssouf Tata Cissé; tradução: Dorothée de Bruchard. Coleção Photo Poche. Vol.12. - São Paulo: Cosac Naify, 2014.

LANDER, Edgardo (org.). A colonialidade do saber: eurocentrismo e ciências sociais - perspectivas latino-americanas. Buenos Aires: CLACSO, 2005.

PEREIRA, Cristiane dos Santos. Coisas do meu pessoal: samba e enredos de raça e gênero na trajetória de Leci Brandão. 2010. Dissertação de Mestrado em História. Brasília: Universidade de Brasília, 2010.

OLIVEIRA NETO. Entre o grotesco e o risível: o lugar da mulher negra na história em quadrinhos no Brasil, 2015.

SANTOS, Elisângela de Jesus. "'São velhas agonias, novas tecnologias': processos criativos e produtivos em meio à canção no cururu paulista", Revista do Instituto de Estudos Brasileiros, n. 59, p. 229-260, dez. 2014a.

SANTOS, Elisângela de Jesus. "Intelectuais e História: identidade caipira e o com-texto civilizatório brasileiro do século XX", Revista História e Cultura. Dossiê História e Sociologia, v.3, n. 3 (Especial), dez, 2014b. 
SOUSA, Fernanda Kalianny Martins. "A Filha da Dona Lecy": estudo da trajetória de Leci Brandão. Dissertação de Mestrado. São Paulo: Faculdade de Letras, Filosofia e Ciências Humanas/USP, 2016.

TRINDADE, Azoilda Loretto. A formação da imagem da mulher negra na mídia. Rio de Janeiro. Tese de Doutorado. Rio de Janeiro: Universidade Federal do Rio de Janeiro/Escola de Comunicação, 2005.

TRINDADE, Azoilda Loretto. Reinventando a roda: experiências multiculturais de uma educação para todos, Africanidades brasileiras e educação, Rio de Janeiro, ACERP, Brasília, TV Escola, 2013.

\section{Fontes Discográficas}

BRANDÃO, Leci. LP Coisas do meu pessoal. Polydor, 1977.

BRANDÃO, Leci. LP Essa tal criatura. Polydor, 1980.

GIL, Gilberto. LP O Luar. Warner, 1981.

\section{Entrevistas}

GARCIA, Januário. Entrevista a Vilma Neres Bispo, 1 áudio digital TASCAM (44min19seg.), Rio de Janeiro, 29 ago. 2014.

\section{Sites}

Dicionário Albin da Música Popular Brasileira. Disponível em: $<$ http://www.dicionariompb.com.br/leci-brandao/dados-artisticos $>$. Acesso em: 28/05/2016. 
$|112|$

Leci e Januário: escrevizências negras...

Grêmio Recreativo Escola de Samba Estação Primeira de Mangueira. Maiores informações institucionais em: <http://www. mangueira.com.br/a-mangueira/historia/historia-da-mangueira/>. Acesso em: 28/05/2016.

Leci Brandão. Entrevista publicada na revista Raça. Disponível em: $<$ https://revistaraca.com.br/leci-brandao-fala-da-vida-politica-ementrevista/>. Acesso em: 18/10/2017.

Assembleia Legislativa do Estado de São Paulo. Disponível em: $<$ https://www.al.sp.gov.br/alesp/deputado/?matricula=300513>. Acesso em: 26/10/2016. 